respiratory syndrome coronavirus (MERS-CoV) infection. Third edition [cited 2016 Aug 26]. http://www.moh.gov.sa/en/CCC/ Regulations/2015\%20update.pdf

7. Corman VM, Müller MA, Costabel U, Timm J, Binger T, Meyer B, et al. Assays for laboratory confirmation of novel human coronavirus (hCoV-EMC) infections. Euro Surveill. 2012;17:20334.

8. World Health Organization. Laboratory testing for Middle East respiratory syndrome coronavirus - interim guidance [cited 2016 Aug 26]. http://www.who.int/csr/disease/coronavirus_infections/ mers-laboratory-testing

9. Assiri AM, Midgley CM, Abedi GR, Bin Saeed A, Almasri MM, Lu X, et al. Epidemiology of a novel recombinant MERS-CoV in humans in Saudi Arabia. J Infect Dis. 2016;214:712-21. http://dx.doi.org/10.1093/infdis/jiw236

10. van Boheemen S, de Graaf M, Lauber C, Bestebroer TM, Raj VS, Zaki AM, et al. Genomic characterization of a newly discovered coronavirus associated with acute respiratory distress syndrome in humans. MBio. 2012;3:e00473-12. http://dx.doi.org/10.1128/ mBio.00473-12

Address for correspondence: Claire M. Midgley, Centers for Disease Control and Prevention, 1600 Clifton Road NE, Atlanta, Georgia, 303294027, USA; email: ydk5@cdc.gov

\title{
Leishmania major Cutaneous Leishmaniasis in 3 Travelers Returning from Israel to the Netherlands
}

\section{Justin S. Kuilder, Pieter J. Wismans, Ewout M. Baerveldt, Jaap J. van Hellemond, Mariana de Mendonça Melo, Perry J.J. van Genderen}

Author affiliations: Harbour Hospital, Rotterdam, the Netherlands (J.S. Kuilder, P.J. Wismans, E.M. Baerveldt, J.J. van Hellemond, M. de Mendonça Melo, P.J.J. van Genderen); Erasmus University Medical Center, Rotterdam, the Netherlands (E.M. Baerveldt, J.J. van Hellemond)

\section{DOI: http://dx.doi.org/10.3201/eid2211.161154}

To the Editor: Cutaneous leishmaniasis (CL) is a protozoan disease transmitted by sand flies that usually runs a relatively mild course. Classic CL starts as a red papule at the place of the insect bite; it gradually enlarges into a painless nodule or plaque-like lesion, which eventually becomes encrusted. When the crust falls off, a typical ulcer with raised and indurated border becomes apparent. CL can cause considerable illness and may leave disfiguring and disabling scars after healing. The interplay between Leishmania species and host immune response is complex, and, as a result, disease manifestations may vary substantially among species as well as among infected persons $(1,2)$. An estimated $0.7-1.2$ million new CL cases occur annually in tropical and subtropical regions of the world. CL is currently endemic in $>98$ countries worldwide; Afghanistan, Algeria, Colombia, Brazil, Iran, Syria, Ethiopia, North Sudan, Costa Rica, and Peru together account for up to $75 \%$ of global estimated CL incidence (3).

We report 3 travel companions from the Netherlands who all acquired CL after they participated in a short-term study course in Israel during September-October 2015. The travelers visited several places in the Negev Desert in southern Israel. All cases were confirmed by PCR with additional sequence analysis of the mini-exon locus and the $3^{\prime}$ untranslated region of the HSP70 locus, demonstrating $L$. major as the causative species (4).

The first case-patient was a 55-year-old man who observed red papules on his head and shoulder 1 month after he returned to the Netherlands. Gradually, these papules increased in size, and number and showed a tendency to ulcerate. On examination at the Institute for Tropical Diseases in Rotterdam, 12 painless, hyperkeratotic, plaquelike, sharply demarcated lesions were identified, some partially ulcerated, located on the head, shoulders, arms, legs, and across the chest. Histopathologic examination on skin biopsy specimens acquired from 1 lesion revealed Leishmania amastigotes, consistent with a diagnosis of CL. The patient was treated with miltefosine $(50 \mathrm{mg}$ orally $3 \times / \mathrm{d}$ for 28 d). Clinical recovery followed gradually.

The second case-patient, a 52-year-old woman, noticed some red papules on both legs that gradually increased in size and ulcerated in the 2 months after return to the Netherlands. She was initially treated by a general practitioner for a presumed bacterial skin infection but did not show a clinical response to antibiotic treatment. On examination, also at the Institute for Tropical Diseases, 6 painless ulcers were seen on her legs. CL was suspected after taking into account the clinical manifestations and the recent diagnosis of CL in her travel companion. She was successfully treated with miltefosine after the diagnosis was confirmed.

A third case-patient, a 52-year-old woman, was diagnosed with CL after she sought treatment for a single small, sharply demarcated, painless pretibial plaquelike skin lesion on her arm that had been present for 2 months after her return to the Netherlands. Repeated PCRs of skin biopsy specimens confirmed the diagnosis of L. major CL. She preferred a "wait and see" policy over treatment.

The 3 patients with CL, a cluster of travel companions, were conceivably infected in the Negev Desert. Only 1 previous report has documented a traveler returning from Israel who was diagnosed with CL at the Institute for Tropical Diseases during 2007-2016 (Table). Most cases originated from the New World, in particular from South America, followed by Central America (Table). Few of these cases 
Table. Characteristics of 3 travel companions to Israel and a cohort of patients with imported cutaneous leishmaniasis previously diagnosed at the Institute for Tropical Diseases, Harbour Hospital, Rotterdam, the Netherlands, 2007-2016

\begin{tabular}{|c|c|c|c|c|}
\hline Characteristics & Case-patient 1 & Case-patient 2 & Case-patient 3 & Cohort, $\mathrm{n}=27^{*}$ \\
\hline New World/Old World & Old World & Old World & Old World & New World: 18 (66.7); Old World: 9 (33.3) \\
\hline Clinical manifestation & $\begin{array}{l}\text { Ulceration/plaque- } \\
\text { like lesion }\end{array}$ & Ulceration & Plaque-like lesion & $\begin{array}{c}\text { Erythematous papule: } 1(3.7) \\
\text { nodule/plaquelike lesion: } 9 \text { (33.3); ulceration: } \\
17(63.0)\end{array}$ \\
\hline Mean no. skin lesions & 12 & 6 & 1 & 1.6 (median 1.0, range $1.0-5.0)$ \\
\hline Localization & $\geq 1$ localization & $\geq 1$ localization & Lower leg & $\begin{array}{c}\text { Face: } 4 \text { (14.8); upper arm: } 3 \text { (11.1); lower } \\
\text { arm: } 10 \text { (37.0); upper leg: 0; lower leg: } 6 \\
\text { (22.2); trunk or neck: } 1 \text { (3.7); } \geq 1 \text { localization: } \\
3(11.1)\end{array}$ \\
\hline Leishmania spp. & L. major & L. major & L. major & $\begin{array}{c}\text { L. major: } 2 \text { (7.4); L. tropica: } 1 \text { (3.7); L. } \\
\text { infantum: } 4 \text { (14.8); L. donovani: } 1 \text { (3.7); L. } \\
\text { mexicana: } 1 \text { (3.7); L.braziliensis: } 7 \text { (25.9); L. } \\
\text { guyanensis: } 4 \text { (14.8); L. panamensis: } 1(3.7) \text {; } \\
\text { L. lainsoni: } 1 \text { (3.7); Unknown: } 5 \text { (18.5) }\end{array}$ \\
\hline Treatment & Miltefosine & Miltefosine & Wait and see & $\begin{array}{c}\text { Cryotherapy: } 2 \text { (7.4); topical } \\
\text { paromomycin/methylbenzethoniumchloride: } 1 \\
\text { (3.7); theurapeutic excision: } 1(3.7) ; \\
\text { fluconazole: } 1 \text { (3.7); pentamidineisethionate: } \\
2 \text { (7.4); systemic stibogluconate: } 3 \text { (11.1); } \\
\text { miltefosine: } 17(63.0)\end{array}$ \\
\hline
\end{tabular}

originated from the Old World, where most of the global effects of $\mathrm{CL}$ occur. $\mathrm{CL}$ is more frequently diagnosed among long-term travelers such as military personnel, adventure travelers, photographers, and researchers, rather than among short-term travelers (5).

Recent reports have described a 7 -fold increase in L. major CL cases among inhabitants of the Negev Desert (6), with urban expansion into CL-endemic foci and changes in land use currently regarded as the most probable causes for this increase in incidence $(6,7)$. A concurrent increase among travelers has not occurred so far, although the aforementioned cases might indicate that the increasing risk of contracting CL in the Negev Desert is not only restricted to its inhabitants but may also pose a risk to short-term travelers.

The spectrum of disease of CL is highly variable, even among persons infected with the same Leishmania species $(1,2,8)$, as illustrated by this cluster of $L$. major CL cases among persons who traveled together to Israel. Because $L$. major CL might mimic other infectious and inflammatory diseases, physicians assessing travelers with painless and persistent skin ulcers after their return from CL-endemic countries should therefore consider CL in their differential diagnosis. In conclusion, awareness should be raised among physicians and healthcare workers that $\mathrm{CL}$ is not exclusively limited to tropical countries but may also be acquired by short-term travelers to more temperate regions, such as southern Europe and the Levant (Syria, Lebanon, Israel, and Jordan) $(3,9)$.

\section{References}

1. Farrar J, Kang G, Hotez PJ, White NJ, Junghanss T, Lalloo D. Manson's tropical diseases, 23rd edition. Philadelphia: Elsevier Saunders; 2013.

2. World Health Organization. Control of the leishmaniases. World Health Organ Tech Rep Ser. 2010;949(xii-xiii):1e186 [cited 2016 Sep 12]. whqlibdoc.who.int/trs/WHO_TRS 949_eng.pdf

3. World Health Organization. Leishmaniasis: epidemiology and access to medicines. Geneva: the Organization; 2012 [cited 2016 Jul 4]. http://www.who.int/leishmaniasis/

4. Van der Auwera G, Ravel C, Verweij JJ, Bart A, Schönian G, Felger I. Evaluation of four single-locus markers for Leishmania species discrimination by sequencing. J Clin Microbiol. 2014; 52:1098-104. http://dx.doi.org/10.1128/JCM.02936-13

5. Mansueto P, Seidita A, Vitale G, Cascio A. Leishmaniasis in travelers: a literature review. Travel Med Infect Dis. 2014;12(6 Pt A):563-81. http://dx.doi.org/10.1016/j.tmaid.2014.09.007

6. Ben-Shimol S, Sagi O, Codish S, Novack V, Barrett C, Fruchtman Y, et al. Dramatic increase in laboratory-diagnosed human cutaneous leishmaniasis cases in southern Israel, 2007-2013. Infect Dis (Lond). 2015;47:161-7. http://dx.doi.org/10.3109/00365 548.2014 .977342 
7. Gandacu D, Glazer Y, Anis E, Karakis I, Warshavsky B, Slater P, et al. Resurgence of cutaneous leishmaniasis in Israel, 2001-2012. Emerg Infect Dis. 2014;20:1605-11. http://dx.doi.org/10.3201/ eid2010.140182

8. Solomon M, Greenberger S, Baum S, Pavlotsky F, Barzilai A, Schwartz E. Unusual forms of cutaneous leishmaniasis due to Leishmania major. J Eur Acad Dermatol Venereol. 2016;30:11715. http://dx.doi.org/10.1111/jdv.13220

9. Ehehalt U, Schunk M, Jensenius M, van Genderen PJ, Gkrania-Klotsas E, Chappuis F, et al. Leishmaniasis acquired by travellers to endemic regions in Europe: a EuroTravNet multi-centre study. Travel Med Infect Dis. 2014;12:167-72. http://dx.doi.org/10.1016/j.tmaid.2013.12.003

Address for correspondence: Perry J.J. van Genderen, Institute for Tropical Diseases, Harbour Hospital, Haringvliet 72, 3011 TG Rotterdam, the Netherlands; email: p.van.genderen@havenziekenhuis.nl

\section{Molecular Evidence of Oysters as Vehicle of Norovirus GII.P17-GII.17}

\section{Lasse Dam Rasmussen, Anna Charlotte Schultz, Katrine Uhrbrand, Tenna Jensen, Thea Kølsen Fischer}

Author affiliations: Statens Serum Institute, Copenhagen,

Denmark (L.D. Rasmussen, T.K. Fischer); Technical University of Denmark, Kongens Lyngby, Denmark (A.C. Schultz, K. Uhrbrand); Danish Veterinary and Food Administration, Glostrup, Denmark (T. Jensen); University of Southern Denmark, Odense, Denmark (T.K. Fischer)

DOI: http://dx.doi.org/10.3201/eid2211.161171

To the Editor: Norovirus is the world's leading cause of nonbacterial acute gastroenteritis (1). Since their emergence, GII.P17-GII.17 noroviruses have replaced the GII.4 Sydney 2012 variant as the dominating norovirus genotype in parts of Asia (2), although they have been detected only sporadically, in a limited number, on other continents (3).

The major reservoir(s) of GII.17 that contribute to transmission are unknown, but it has been suggested that oysters and other bivalve shellfish are common vehicles for transmission of the emerging GII.17 viruses (2). In this study, we demonstrate the link between oysters and human disease by presenting molecular evidence of norovirus GII. P17-GII.17 in Denmark causing acute gastroenteritis, characterized by the sudden onset of vomiting with or without diarrhea after consumption of oysters. We further document molecular evidence providing linkage between norovirus detected in fecal samples from patients and food samples from imported oysters.
During January 23-February 4, 2016, acute gastroenteritis developed in 58 of 67 persons who consumed oysters served on 18 separate occasions at 8 different restaurants and a private party, with onset of symptoms within 24-40 hours after the patients ate oysters. All oysters originated from 2 distinct oyster lots provided by 1 wholesaler in France and distributed by 1 wholesaler in Denmark. Oysters from both lots were harvested off the coast of La Rochelle, France.

In Denmark, submitting fecal samples in connection with foodborne outbreaks is voluntary. A total of 5 samples from 3 cases representing 2 different parties were submitted to the National Virus Surveillance Laboratory at Statens Serum Institut (Copenhagen, Denmark) for norovirus analysis. In addition, 4 samples of oysters from the same producer in France were sent to the National Food Institute, Technical University of Denmark (Kongens Lyngby, Denmark), for norovirus analysis. Two samples, an opened (sample A) box and an unopened (sample B) box collected at one of the restaurants involved in the outbreak, contained oysters from 1 batch (I), and another 2 samples (C and D) contained oysters from a separate batch (II) collected at the wholesale level.

Norovirus in fecal samples was detected and polymerase (open reading frame [ORF]1) and capsid (ORF2) gene regions were amplified as described elsewhere (4). Sequencing was performed by using an ABI 3500 genetic analyzer (Thermo Fisher Scientific, Nærum, Denmark). A fragment of 1,111 nt spanning the ORF1-ORF2 junction was amplified and sequenced by using forward ORF1 primer JV12 and reverse ORF2 primer G2SKR (4). Genotyping was performed by using the Web-based norovirus typing tool NoroNet (http://www.rivm.nl/mpf/norovirus/typingtool) (5).

We found that all fecal samples contained norovirus belonging to genogroup II (GII). Sequencing of the polymerase region was successful in 4 of the 5 samples; all 5 samples were sequenced in the capsid region. Typing of the sequences indicated GII.P17 and GII.17, respectively. Furthermore, PCR and sequencing of the long fragment covering the ORF1-ORF2 junction were successful in 2 samples, both genotyping as GII.P17-GII.17. Sequences had high homology (99.91\%) to several Asian strains, such as Hu/GII.P17_GII.17/KR/2014/CAU-265 (6).

Oysters were analyzed for norovirus (7), and the capsid region of the detected strains was sequenced (8). Samples $\mathrm{A}, \mathrm{B}$, and $\mathrm{C}$ contained norovirus GI, whereas all 4 samples (A-D) contained norovirus GII. GI.2 was identified in 1 sample (B), and GII.17 was identified in all samples (A-D). The GII.17 sequences obtained from samples A-C showed $100 \%$ homology, whereas the sequence identified in sample $\mathrm{D}$ varied at 3 positions.

Comparisons of the capsid sequences obtained from 4 human samples and oyster samples A-C showed 100\% 